\title{
GENES BIOMARKERS IN AUTISM: BRAIN DEVELOPMENT AND FUNCTION
}

\author{
Dahrizal Dahmayanti Saridewi, Abdul Karim Norwahidah
}

Department of Biochemistry, Faculty of Medicine, Universiti Kebangsaan Malaysia, Cheras, Malaysia

\section{ABSTRACT}

Autism is childhood neuropsychiatric disorder despite exhibiting high heritability and has largely eluded efforts to identify specific genetic variants of biomarkers. This neuropsychiatric disorder is characterized by social and communicative deficits and ritualistic-repetitive behaviour that are detectable in early childhood. It has been reported that some candidate genes has been found in autism children brains. The candidate genes include aspects of neurogenesis, neuronal migration, maturation, differentiation, and degeneration. Some of researchers had reported the effects of the mutated and sufficiency of the candidate genes in autism brain which believed that might involved in the mechanism and causes deficit in social behaviour language impairment and repetitive behaviour. In this review, we will summarize the gene candidate which found in autism children brains and their effect of their cognitive function.

KEYWORDS: Autism; Gene biomarkers; Brain development.

\section{INTRODUCTION}

Autism is a childhood neuropsychiatric disorder despite exhibiting high heritability, has largely eluded efforts to identify specific genetic variants underlying its etiology [1]. It presents with a triad of core symptoms which include a qualitative impairment of social interaction (an inability to relate to others often with lack of eye contact), stereotypical, ritualistic, repetitive, restrictive patterns of interests, behaviours and activities, and major defects in language development and in other communication skills. Other non-specific symptoms also found in autism such as unusual sensory perception skills and experiences, motor clumsiness, insomnia, and limited intelligence (IQ > 100 in $5 \%$ ) [2]. Autism spectrum disorders (ASDs) is composed of three separate diagnoses that include autism and two other milder but qualitatively similar disorders, Asperger's syndrome and Pervasive Developmental Delay Not otherwise Specified (PDD-NOS). The wide spectrum of developmental disorders characterized by impairments in 3 behavioural domains: social interaction, language (including communication and imaginative play), and range of interests and activities [3]. This neurodevelopmental disorder is characterized by social and communicative deficits and ritualisticrepetitive behaviours that are detectable in early childhood. As one of the most heritable ( $>90 \%$ herita-

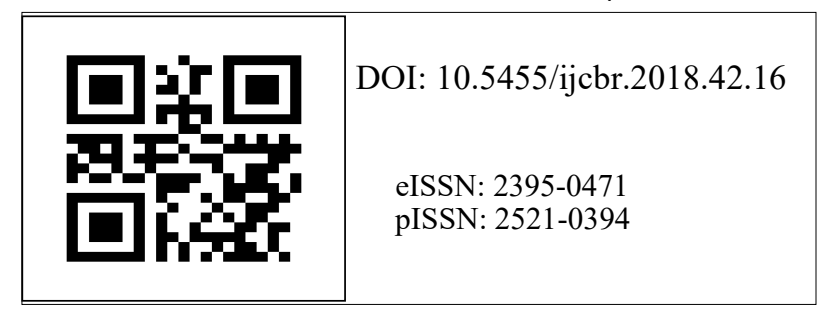

bility) genetic disorders, autism is classified as a 'pervasive developmental disorder' - pervasive because it affects many aspects of cognition, behaviour and developmental since autistic symptoms emerge during development from infancy or perhaps from birth [4].

The term "idiopathic" autism is refers to cases in which children meet the criteria for ASDs but do not have any associated medical condition known to cause ASDs. Children with idiopathic ASDs demonstrate variable behavioural phenotypes, are somewhat less likely to have comorbid with Global Developmental Delay (GDD) or Mental Retardation (MR), and generally do not have dysmorphic features that herald a recognizable syndrome [5]. Recently, many candidate genes has been associated with ASDs, but no single allele is ordinary described the symptom. Besides, the environment also believed to play a role in ASDs. Many conflicting theories have been presented to explain the environmental components of the disease including aspects of nutrition, economic status, vaccination, and general health care as well as environmental pollutants and family life [6]. However, none of these environmental parameters have been shown to be commonly linked to ASDs. It has reported that the anomalies of ASDs include the high incidence in middle and upper middle class young children as opposed to underprivileged kids living in poverty [7].

The candidate genes include aspects of neurogenesis, neuronal migration, maturation, differentiation, and degeneration. There are also striking examples of

Corresponding author: Norwahidah Abdul Karim, Department of Biochemistry, Faculty of Medicine, University Kebangsaan Malaysia, Cheras, Malaysia..Email: wahida2609@gmail.com 
overexpression of certain regions of the prefrontal cortex and cerebellum in general, as well as multiple sites of dysregulation in both the innate and acquired immune response [8]. The regulation of expression of some autism candidate genes by neuronal membrane depolarization suggests the appealing hypothesis that neural activity-dependent regulation of synapse development may be a mechanism common to several autism mutations. Early brain development is driven largely by intrinsic patterns of gene expression that do not depend on experience-driven synaptic activity as reported by [9].

The search for candidate genes for autism is complicated by the fact that the majority of genes associated with the disorder are associated with only one specific symptom. The specific genes are contributes to specific symptoms, such as social difficulties, communication deficits, or repetitive behaviours. The gene candidates such as En2,[10] reelin [11] GABRB3 [12] AVPR1A [13] CADPS2 [14] and FOXP2 [15].

Engrailed-2 : Human Engrailed-2 (En2) gene is localized to 7q36, an autism susceptibility locus. This genes were introduced on mouse since 2005[10, 16-20]. However, it is also found in human brain study [21]. The homeobox-containing transcription factor En2 is involved in patterning and neuronal differentiation of the midbrain/hindbrain region, where it is prominently expressed. En2 mRNA is also expressed in the adult mouse hippocampus and cerebral cortex, indicating that it might also function in these brain areas. Genome-wide association studies revealed that En2 is a candidate gene for autism spectrum disorders (ASDs), and mice devoid of its expression (by using EN2-/mice) display anatomical, behavioural and clinical "autistic-like" features [19].

Recent human genetic studies are consistent with the homeobox transcription factor En2, being an ASD susceptibility gene. The En2 knockout mice (EN2--/-) display subtle cerebellar neuropathological changes similar to what has been observed in the ASDs brain.(18) The En2 knockout mice display hypoplasia of cerebellum and a decrease in the number of Purkinje cell, which are similar to those reported for individuals with autism [19]. The normal EN-2 downregulation that signals Purkinje cell maturation during late prenatal and early-postnatal development may not have occurred in some individuals with autism and that the postnatal persistence of EN-2 overexpression may contribute to autism cerebellar abnormalities as reported by [21]. The disturbance in En2 signaling may contribute to neuropsychiatric disorders marked by social and cognitive deficits, including autism spectrum disorders as reported by [10].

Reelin (RELN): It has been reported that Reelin plays a pivotal role in the development of laminar structures including the cerebral cortex, hippocampus, cerebel- lum and of several brainstem nuclei [22]. Neuroanatomical evidence is consistent with Reelin involvement in autistic children. Reelin is an important secretory glycoprotein responsible for normal layering of the brain. B-Cell lymphoma $2(\mathrm{Bcl}-2)$ is a regulatory protein responsible for control of programmed cell death in the brain. It has been reported recently that longer triplet repeats in the 5' UTR of the Reelin gene confer vulnerability to autistic disorder [23]. Current researches were reported that Reelin was found and expressed on cerebellar cortex [22,24-26]. It was reported that dysregulation of Reelin and $\mathrm{Bcl}-2$ may be responsible for some of the brain structural and behavioural abnormalities observed in autism then followed by quantification of Reelin and Bcl-2bands showed reductions in autistic cerebellum. Measurement of $\beta$-actin in the same homogenates did not differ significantly [22].

Recent genetic linkage studies implicate Reelin glycoprotein in the causation of autism. Reelin deficiency may contribute to structural abnormalities as well as with abnormal synaptic connectivity. Reduced Reelin expression may result from epigenetic effects such as hypermethylation of the Reelin promoter, early developmental events such as activation of the maternal immune system during gestation. In the other study, mRNA for Reelin was significantly reduced in frontal cortex and cerebella of subjects with autism, consistent with the protein data as was mRNA for Disable1 (DAB1). In contrast, mRNA for Very low density lipoprotein receptor (VLDLR) was significantly increased in both areas, which may be a compensatory mechanism for reduced expression of Reelin [26].

GABRB3 : Gamma-aminobutyric acid (GABA) is the main inhibitory neurotransmitter in the brain. A cluster of GABAA receptor subunit genes, including GABRB3, GABRA5, and GABRG3, which encode subunits $\beta 3, \alpha 5$, and $\gamma 3$ respectively, were mapped to chromosome 15q12 [28]. The reduced expression of GABAA receptor subunits including GABRB3 and the GABA synthesizing enzymes, glutamic acid decarboxylase (GAD) 65 and 67 were found in several brain regions of patients with autism.[24,28,29]. GABRB3 is a position candidate gene at chromosome $15 q 21$ that has been implicated in the neurobiology of ASDs. The altered GABRB3 gene expressions are likely involved in the neurobiology of ASDs. The GABRB 3 is biallelically expressed in control brain tissue samples.[12]

The association and linkage study for the $\gamma$ aminobutyric acid type $A$ receptor $\beta 3$ subunit gene GABRB3 which is located within the chromosome 15q11-q13 autism candidate region and ASDs have been evaluated. A study demonstrated with a detection of four single-nucleotide polymorphisms in GABRB3. The results demonstrated that a marker of GABRB3 haplotype test transmission did not reveal any association between GABRB3 and ASD. The find- 
ing suggested that single-nucleotide polymorphisms in GABRB3 may play a significant role in the genetic predisposition to ASD [30].

Maternal Chromosome $15 q 11-q 13$ is a hot region occurrence of genomic DNA deletions and duplications that are usually associated with developmental disorders including ASD. The maternal duplication of $15 q 11$ -q13 was found in approximately 1 to $3 \%$ of patients with ASD [31,32]. The $15 q 11-13$ region is subject to epigenetic regulations, genomic copy number losses and gains cause genomic disorders in a parent-oforigin-specific manner. The analysis of wild-type and mutant $\beta 3$ subunit-containing $\alpha 1 \beta 3 \gamma 2$ or $\alpha 3 \beta 3 \gamma 2$ GABAA receptors shows reduced whole-cell current and decreased $\beta 3$ subunit protein on the cell surface due to impaired intracellular $\beta 3$ subunit processing. The study reported of an association between a specific GABAA receptor defect and autism which had direct evidence that this defect causes synaptic dysfunction that is autism relevant and the first maternal risk effect in the 15q11-q13 autism duplication region that is linked to a coding variant [32].

GABA-ergic system has been associated consistently with atypicalities in autism, in both genetic association and expression studies. A key component of the GABA -ergic system is encoded by the GABRB3 gene, which has been previously implicated both in ASD and in individual differences in empathy. The current study confirms the role of GABRB3 as an important candidate gene in both ASD and normative variation in related endophenotypes [33].

AVPR1A: Impairment in social reciprocity is a central component of autism. In mammals, the neuropeptide vasopressin is a key molecule for complex emotional and social behaviours [34]. Two microsatellite polymorphisms, RS1 and RS3, near the promoter of AVPR1A, encoding the receptor subtype most heavily implicated in behaviour regulation have been linked to autism and behavioural traits [13,34]. Arginine vasopressin (AVP) has been shown to increase a range of social behaviours, including affiliation and attachment, via the V1a receptor (AVPR1A) in the brain. Both of behavioural effects of AVP and the neural distribution of the V1a receptor vary greatly across mammalian species. This difference in regional receptor expression as well as differences in social behaviour may result from a highly variable repetitive sequence in the 5 ' flanking region of AVPR1A [34]. The current study reported that AVPR1A gene in individuals showing deficits in social behavior that associated with autism [35]. A neural mechanism mediating genetic risk for autism through an impact on amygdala signalling and provide a rationale for exploring therapeutic strategies aimed at abnormal amygdala function in this disorder $[13,34]$.

CADPS2: Intellectual disability (ID) and Autism spec- trum disorders (ASDs) are complex neuropsychiatric conditions, with overlapping clinical boundaries in many patients [36]. CADPS2 is an excellent candidate for neurologic development abnormalities, given that it is predominantly expressed in the nervous system $[37,38]$. This gene is one of the genes that was shown to be down regulated in autism brain patient. CADPS2 is maternally expressed in human blood and amygdala. Using Array-CGH analysis, an intragenic deletion of $\sim 285 \mathrm{~kb}$ in CADPS2 on chromosome 7q31.32 on siblings were detected, likely inherited from the deceased mother, since the father did not carry it. Submicroscopic deletions in 7q31 encompassing CADPS2 (Ca2+-dependent activator protein for secretion 2) and TSPAN12 (one of the members of the tetraspanin superfamily) has confirmed. The CADPS2 plays important roles in the release of neutrophin-3 and brainderived neurotrophic factor. Mutations in TSPAN12 are a relatively frequent cause of familial exudative vitreoretinopathy. It is speculated that haploinsufficiency of CADPS2 and TSPAN12 would contribute to ASDs [14].

FOXP2: The FOXP2 gene is located on human 7q31 (at the $\mathrm{SPCH} 1$ locus). It is encodes a transcription factor containing a polyglutamine tract and forkhead domain. FOXP2 is mutated in a severe monogenic form of speech and language impairment, segregating within a single large pedigree, and is also disrupted by a translocation in an isolated case. Several studies of autistic disorder have demonstrated linkage to a similar region of 7q (the AUTS1 locus), leading to the proposal that a single genetic factor on $7 q 31$ contributes to both autism and language disorders. It was hypothesized that coding-region variants in FOXP2 do not underlie the AUTS1 linkage and that the gene is unlikely to play a role in autism or more common forms of language impairment [15].

The receptor tyrosine kinase (MET) regulates neuronal differentiation and growth is associated in autisticspectrum disorder. An ASD-associated polymorphism disrupts MET gene transcription are reduced levels of MET protein expression in the mature temporal cortex of subjects with ASD. The expression and transcriptional regulation of MET by a transcription factor, FOXP2, which is implicated in regulation of cognition and language, two function altered in ASD. Consistent with this, MET and FOXP2 also are reciprocally expressed by differentiating normal human neuronal progenitor cells (NHNPs) in vitro, is a way to assessed whether FOXP2 transcriptionally regulates MET. As FOXP2 binds directly to 5 ' regulatory region of MET, and overexpression of FOXP2 results in transcriptional repression of MET in restricted human neocortical regions, and its regulation in part by FOXP2, is consistent with genetic evidence for MET contributing to ASD risk [39]. 
Table 1. Number of genes which known functions are affected in ASD.

\begin{tabular}{|l|l|l|}
\hline Gene & Function & Effect \\
\hline ENGRAILED2 & $\begin{array}{l}\text { Patterning and neuronal differentiation of the } \\
\text { midbrain/hindbrain region }\end{array}$ & $\begin{array}{l}\text { Display anatomical, behavioural, } \\
\text { and clinical "autistic-like" feature }\end{array}$ \\
\hline Reelin & $\begin{array}{l}\text { Privotal role in the development of laminar } \\
\text { structures including the cerebral cortex, hippo- } \\
\text { campus, cerebellum and of several brainsteam } \\
\text { nuclei }\end{array}$ & $\begin{array}{l}\text { Responsible for brain structural and } \\
\text { behavioural abnormalities observed } \\
\text { in autism }\end{array}$ \\
\hline GABRB3 & Main inhibitory neurotransmitter in the brain & $\begin{array}{l}\text { Deficits in social interaction and } \\
\text { communication, alongside repeti- } \\
\text { tive, restricted, and stereotyped } \\
\text { behaviour }\end{array}$ \\
\hline AVPR1A & $\begin{array}{l}\text { A key molecule for complex emptional and social } \\
\text { behaviours }\end{array}$ & $\begin{array}{l}\text { Mediating genetic risk for autism } \\
\text { through an impact on amygdala } \\
\text { signalling and aimed an abnormal } \\
\text { amygdala function in autism }\end{array}$ \\
\hline CDPS2 & Neurologic development abnormalities & $\begin{array}{l}\text { Haplosufficiency of it may contrib- } \\
\text { utes to ASDs }\end{array}$ \\
\hline FOXP2 & Pairment & $\begin{array}{l}\text { Severe monogenic form of speech } \\
\text { and language impairment, segre- } \\
\text { gating within a single large pedigree }\end{array}$ \\
\hline
\end{tabular}

\section{CONCLUSION}

Several previous findings had reported the effects of the mutated and sufficiency of the candidate genes in autism brain. It is believed that they might be involved in the mechanism that cause deficit in social behaviour language impairment, and repetitive behaviour. However, there are abundant of genes that most probably contribute to clinical "autistic-like" feature, brain structural abnormalities, and deficit in social interaction and communication along with repetitive, restricted and stereotyped behaviour which had not yet significantly correlated.

\section{REFERENCE}

1) Arking DE, Cutler DJ, Brune CW, Teslovich TM, West $\mathrm{K}$. A common genetic variant in the neurexin superfamily member CNTNAP2 increases familial risk of autism. The American Journal of Human Genetics. 200882: 160-164.

2) Gharani N, Benayed R, Mancuso V, Brzustowics LM, Millonig JH. Association of the homeobox transcription factor, ENGRAILED 2, 3, with autism spectrum disorder. Molecular Psychiatry. 2004;9(5): 474-84.

3) Muhle R, Trentacoste SV, Rapin I. The genetics of autism. Pediatrics. 2004;113(5): e472-86.

4) Anitha A, Nakamura K, Thanseem I. Brain regionspecific altered expression and association of mito- chondria-related genes in autism. Mol Autism.2012;3 (1): 12.

5) Johnson CP, Myers SM, American Academy of Pediatrics Council on Children With Disabilities. Identification and evaluation of children with autism spectrum disorders. Pediatrics. 2007; 120(5): 1183-215.

6) Morrow EM, Yoo SY, Flavell SW. Identifying autism loci and genes by tracing recent shared ancestry. Science. 2008;321(5886): 218-23.

7) Maski KP, Jeste SS, Spence SJ. 2011. Common neurological co-morbidities in autism spectrum disorders. Curr Opin Pediatr 23(6): 609-15.

8) Guerra DJ. The molecular genetics of Autism Spectrum Disorders: genomic mechanisms, neuroimmunopathology, and clinical implications. Hindawi Publishing Corporation. 2011

9) Christopher WA, Morrow EM, Rubenstein JLR. Autism and brain development. Cell. 2008;135(3): 396 -400 .

10) Brielmaier J, Matteson PG, Silverman JL, Senerth JM, Kelly S, Genestine M, et al. 2Autism-relevant social abnormalities and cognitive deficits in Engrailed-2 knockout mice. Plos One. 2012 7(7): e40914.

11) Fatemi SH, Stary JM, Halt AR, Realmuto GR. Dysregulation of Reelin and $\mathrm{Bcl}-2$ proteins in autistic cere- 
bellum. Journal of Autism and Developmental Disorders. 2001;31(6): 529-535.

12) Chen $\mathrm{CH}$, Huang $\mathrm{CC}$, Cheng MC, Chiu YN, Tsai WC, Wu YY, Liu SK, Gau SS. Genetic analysis of GABRB3 as a candidate gene of autism spectrum disorders. Molecular Autism. 2014;5: 36.

13) Meyer-Lindenberg A, Kolachana B, Gold B. Genetic variants in AVPR1A linked to autism predict amygdala activation and personality traits in healthy humans. Mol Psychiatry 2009;14(10): 968-75.

14) Okamoto N, Hatsukawa $Y$, Shimojima K, Yamamoto T. Submicroscopic deletion in 7q31 encompassing CADPS2 and TSPAN12 in a child with autism spectrum disorder and PHPV. American Journal of Medical Genetics Part A. 2011;155(7): 1568-1573.

15) Newbury DF, Bonora E, Lamb JA, Fisher SE, Lai CS. FOXP2 is not a major susceptibility gene for autism or specific language impairment. Am J Hum Genet. 2002;70(5): 1318-1327.

16) Benayed R, Gharani N, Rossman I, Mancusco V. Support for the homeobox transcription factor gene ENGRAILED 2 as an autism spectrum disorder susceptibility locus. Am J Hum Genet. 2005;77(5): 851-68.

17) Benayed R, Choi J, Matteson PG, Gharani N. Autism associated haplotype affects the regulation of the homeobox gene, ENGRAILED 2. Biol Psychoatry.2009;66(10): 911-917.

18) Cheh MA, Millonig JH, Roselli LM, Ming X. En2 knockout mice display neurobehavioral and neurochemical alterations relevant to autism spectrum disorder. Brain Re 2006;1116(1): 166-76.

19) Wang L, Jia M, Yue W, Tang F. Association of the ENGRAILED 2 (EN2) gene with autism in Chinese Han population. Am J Med Genet B Neuropsychiatry Genet. 2008; 147B(4): 434-8.

20) Sgado P, Provenzano G, Dassi E, Adami V. Transcriptome profiling in engrailed-2 mutant mice reveals common molecular pathways associated with autism spectrum disorders. Molecular Autism. 2013;4(51).

21) James SJ, Shpyleva S, Melnyk S, Pavliv O, Pogribny IP. Complex epigenetic regulation of Engrailed-2 (EN-2) homeobox gene in the autism cerebellum. Translational Psychiatry.2013;3: e232.

22) Fatemi SH, Stary JM, Halt AR, Realmuto GR. Dysregulation of Reelin and $\mathrm{Bcl}-2$ proteins in autistic cerebellum. J Autism Dev Disord. 2001;31(6): 529-35.

23) Persico AM, D’Agruma L, Maiorano N, Totaro A, Militerni R. Reelin gene alleles and haplotypes as a factor predisposing to autistic disorder. Mol Psychi- atry. 2001;6(2): 150-9.

24) Fatemi SH, Halt AR, Stary JM, Kanodia R, Schulz SC, Realmuto GR. Glutamic acid decarboxylase 65 and $67 \mathrm{kDa}$ proteins are reduced in autistic parietal and cerebellar cortices. Biol Psychiatry. 2002;52: 805810 .

25) Fatemi SH, Snow AV, Stary JM, Araghi-Niknam M. Reelin signalling is impaired in autism. Biological Psychiatry. 200457 (7): 77-787.

26) Fatemi SH. Reelin glycoprotein in autism and schizophrenia. International Review of Neurobilogy. 2005;71: 179-187.

27) Sutcliffe J, Nurmi E. Duplication and inherited susceptibility of chromosome 15q11-q13 genes in autism. J Am Acad Child Adolesc Psychiatry. 2003;42: 253-256.

28) Yip J, Soghomonian JJ, Blatt GJ. Decreased GAD67 mRNA levels in cerebellar Purkinje cells in autism: pathophysiological implications. Acta Neuropathologica. 2007;113:559-568.

29) Yip J, Soghomonian JJ, Blatt GJ. Decreased GAD65mRNA levels in select subpopulations of neurons in the cerebellar dentate nuclei in autism: an in situ hybridization study. Autism Res. 2009; 2: 50-59.

30) Kim JA, Szatmari P, Bryson SE, Streiner DL, Wilson FJ. The prevalence of anxiety and mood problems among children with autism and Asperger syndrome. Autism. 2000;4: 117-132.

31) Abrahams BS, Geschwind DH. Advances in autism genetics: on the threshold of a new neurobiology. Nat Rev Genet. 2008;9(5): 341-55.

32) Delahanty RJ, Kang JQ, Brune, CW. Maternal transmission of a rare GABRB3 signal peptide variant is associated with autism. Molecular Psychiatry.2011;16: 86-96.

33) Warrier V, Baron-Cohen S, Chakrabarti B. Genetic variation in GABRB3 is associated with Asperger syndrome and multiple endophenotypes relevant to autism. Mol Autism. 2013;4(1): 48.

34) Kim SJ, Young LJ, Gonen D, Veenstra-VanderWeele J, Courchesne R, et al. Transmission disequilibrium testing of arginine vasopressin receptor $1 \mathrm{~A}$ (AVPR1A) polymorphisms in autism. Mol Psychiatry. 2007;7(5): 503-7.

35) Yirmiya N, Rosenberg C, Levi S, Salomon S.. Association between the arginine vasopressin 1a receptor (AVPR1a) gene and autism in a family-based study: mediation by socialization skills. Molecular Psychiatry. 2006;11: 488-494 
36) Bonora E, Graziano C, Minopoli F, Bacchelli E, Magini $P$. Maternally inherited genetic variants of CADPS2 are present in Autism Spectrum Disorders and intellectual disability patients. EMBO Mol Med. 2014;6(6): 795-809.

37) Sadakata T, Furuichi T. Developmentally regulated Ca2+-ependent activator protein for secretion 2 (CAPS2) is involved in BDNF secretion and is associated with autism susceptibility. Cerebellum. 2009;8 (3): 312-22.

38) Sadakata T, Furuichi T. $\mathrm{Ca}(2+)$-dependent activator protein for secretion 2 and autistic-like phenotypes. Neuroschi Res. 2010;67(3): 197-202.

39) Mukamel Z, Konopka G, Wexler E, Osborn GE, Dong $H$, Bergman MY, Levitt P, Geshcwind DH. Regulation of MET by FOXP2, genes implicated in higher cognitive dysfunction and autism risk. The Journal of Neuroscience2011;31(32): 11437-11442.

How to Cite this article: Dahrizal Dahmayanti Saridewi, Abdul Karim Norwahidah. Genes biomarkers in autism: brain development and function. Int. j. clin. biomed. res. 2018;4(2): 74-79. 